\title{
PROTECCIONES DEL PATRIMONIO HISTÓRICO URBANO EN CHILE
}

\author{
Protection of the heritage urban history in Chile
}

\section{José Fernández Richard ${ }^{1}$}

\begin{abstract}
Sumario:
I. Generalidades. II. Categorías de protección al patrimonio cultural urbano en la ley 17.288. III. Procedimiento para declarar un monumento como histórico. IV. Efectos de la declaración de monumento histórico. V. Análisis crítico de la ley 17.288. VI. Declaración de zona típica. VII. Delitos y acción procesal establecidos en la ley 17.288. VIII. Conclusiones. IX. Fuentes de consulta.
\end{abstract}

Resumen: Chile es un país con escasos monumentos nacionales, por lo tanto mayor es el deber de protegerlos para evitar su ruina y destrucción. A este objetivo obedece la ley 17.288 sobre monumentos nacionales, que permite proteger los monumentos históricos y establecer zonas típicas - sin embargo una de las falencias de esta legislación es que no contempla incentivos tributarios para los propietarios de dichos inmuebles

Palabras claves: monumentos históricos, su protección legal, ausencia de incentivos tributarios para el dueño del inmueble

Summary: Chile is a country with scarce national monuments, therefore the greater is the duty to protect to avoid their ruin and destruction. To this objective obeys the law 17.288 on national monuments, that allows you to protect the historical monuments typical areas and establish. However, one of the weaknesses is that it does not cover incentives Tax for the owners of these buildings.

Keywords: historical monuments, Its legal protection, absence of tax incentives for the owner of the property.

\section{GENERALIDADES}

1. Chile es un país con pocos monumentos nacionales, por lo tanto mayor es el deber de conservarlos y preservarlos, impidiendo su ruina y destrucción y es por ello que se creó El

\footnotetext{
${ }^{1}$ Abogado Especialista en Derecho Administrativo, y en especial en Derecho Municipal, ejerce actualmente la docencia como profesor titular de Derecho Urbanístico Municipal en la Universidad de Chile y en diversas Universidades del país, es autor de las siguientes obras: "Las Patentes Municipales”; "Régimen Jurídico de la Administración Municipal”; "Derecho Municipal chileno"; "Derecho Administrativo chileno", se ha desempeñado como Abogado Jefe de la Municipalidad de Santiago, y como Abogado Integrante de la Excma. Corte Suprema de Justicia por un periodo de 18 años.
} 
Consejo de Monumentos Nacionales de Chile, que sigue las recomendaciones de la Unesco, efectuadas en Paris el año 1968.

Es así que tal como lo indica la ley 17.288 sobre la materia, en su título II, artículo $2^{\circ}$ dispone: "El Consejo de monumentos nacionales es un organismo técnico que depende directamente del Ministerio de Educación Pública", siendo a su vez un órgano colegiado que forma parte de la administración centralizada de Chile, y su principal propósito es ejercer la tuición y protección de los monumentos nacionales. Desde la dictación de la ley 19.891 queda bajo la coordinación del Consejo de la Cultura y las Artes en lo referente a sus políticas, planes, programas y acciones.

2. Composición del Consejo de Monumentos Nacionales. El Consejo de Monumentos Nacionales se compone de 21 miembros provenientes de una variada gama de actividades relacionadas con la política, las ciencias, las artes, el patrimonio y la cultura del país. Sus miembros son representantes de las más importantes entidades culturales (artículo $2^{\circ}$ ): y es presidido por el Ministro de Educación.

3. El Presidente de la República designa cada tres años, a los miembros del Consejo que no lo sean por derecho propio, a propuesta de las respectivas instituciones.

4. Además con las modificaciones impuestas por la ley que creó el Consejo Nacional de la Cultura y las Artes, se incorporó un nuevo miembro al Consejo, consistente en un representante del Consejo Nacional de la Cultura y las Artes.

Lo mismo ocurre con las modificaciones añadidas por la ley 20.423 del Sistema Institucional para el Desarrollo del Turismo, que aseguran un nuevo miembro que es un representante del Servicio Nacional del Turismo.

5. Atribuciones y deberes del Consejo de Monumentos Nacionales

El artículo 61 de la ley sobre Monumentos Nacionales estipula cuales son las atribuciones y deberes del Consejo de monumentos nacionales, para una mejor comprensión dividiremos estas funciones en las siguientes tres categorías:

I. Atribuciones de Constitución, identificación y registro de Monumentos:

1. Pronunciarse sobre la conveniencia de declarar monumentos nacionales los lugares, ruinas, construcciones u objetos que estime del caso y solicitar de la autoridad competente la dictación del decreto supremo correspondiente. (Artículo $6^{\circ} \mathrm{N}^{\circ} 1$ ).

2. Formar el Registro de monumentos nacionales y museos. (Artículo $6^{\circ}$ № 2).

3. Gestionar la reivindicación o la cesión o venta al Estado o la adquisición a cualquier título por éste, de los monumentos nacionales que sean de propiedad particular. (Artículo $\left.6^{\circ} \mathrm{N}^{\circ} 4\right)$.

II. Definición e implementación de política

1. Elaborar los proyectos o normas de restauración, reparación, conservación y señalización de los monumentos nacionales y entregar los antecedentes a la Dirección de Arquitectura del Ministerio de Obras Públicas y Transportes para la ejecución, de común acuerdo, de los trabajos correspondientes, sin perjuicio de las obras que el Consejo pudiera realizar por si mismo o por intermedio de otro organismo y para cuyo financiamiento 
se consultaren o se recibieren fondos especiales del Presupuesto de la Nación o de otras fuentes. (Artículo $6^{\circ} \mathrm{N}^{\circ} 3$ ).

2. Reglamentar el acceso a los monumentos nacionales y aplicar o, en su defecto, proponer al Gobierno las medidas administrativas que sean conducentes a la mejor vigilancia y conservación de los mismos. (Artículo $6^{\circ} \mathrm{N}^{\circ} 5$ ).

3. Proponer al Gobierno el o los reglamentos que deban dictarse para el cumplimiento de la presente ley. Artículo $6 \mathrm{~N}^{\circ} 7$ ).

III Supervigilancia y control sobre monumentos nacionales

1. Conceder los permisos o autorizaciones para excavaciones de carácter histórico, arqueológico o paleontológico en cualquier punto del territorio nacional, que soliciten las personas naturales o jurídicas chilenas o extranjeras en la forma que determine el Reglamento. (Artículo $6^{\circ} \mathrm{N}^{\circ} 6$ ).

\section{CATEGORÍAS DE PROTECCIÓN AL PATRIMONIO CULTURAL URBANO EN LA LEY 17.288}

En materia de inmuebles patrimoniales la ley en análisis establece las siguientes categorías de protección:

I. Monumentos históricos, que en su título III llamado "De los monumentos Históricos" y que el artículo $9^{\circ}$ define como: los lugares, ruinas, construcciones y objetos de propiedad fiscal, municipal o particular que por su calidad e interés histórico o artístico o por su antigüedad, sean declarados tales por decreto supremo, dictado a solicitud y previo acuerdo del Consejo.

II. Zonas Típicas, que en su Título VI denominado "De la Conservación de los caracteres Ambientales", artículo $29^{\circ}$ les otorga el siguiente tratamiento: "Para el efecto de mantener el carácter ambiental y propio de ciertas poblaciones o lugares donde existieren ruinas arquelógicas o ruinas y edificios declarados Monumentos Históricos, el Consejo de monumentos nacionales podrá solicitar se declare de interés público la protección y conservación del aspecto típico y pintoresco de dichas poblaciones o lugares o de determinadas zonas de ellas.”

\section{PROCEDIMIENTO PARA DECLARAR UN MONUMENTO COMO HISTÓRICO}

La regla general la encontramos en el artículo 10 de la ley de Monumentos Nacionales que señala "Artículo $10^{\circ}$-Cualquiera autoridad o persona puede denunciar por escrito ante el Consejo la existencia de un bien mueble o inmueble que pueda ser considerado Monumento Histórico, indicando los antecedentes que permitirían declararlo tal."

Ahora bien, la regulación específica del procedimiento para la declaración de un inmueble como monumento nacional o de un lugar como zona típica, se encuentra en un documento de trabajo publicado por el Consejo de monumentos nacionales denominado "Procedimiento para la declaración de un monumento nacional y requisitos mínimos para presentar una solicitud de declaración" del año 2007. En él se señala en líneas generales que una vez ingresada la solicitud, esta pasa al análisis de la comisión del área respectiva del Consejo, en este caso la Comisión de Arquitectura o la Comisión de Patrimonio Histórico (existiendo también la Comisión de Arqueología y la Comisión de Patrimonio Natural). Con el informe 
positivo de esta Comisión, la solicitud pasa al Consejo pleno, que en su sesión mensual vota en definitiva.

Señala el documento a su vez que desde 1994, y por Resolución del Ministro de Educación, se exige un antecedente muy importante: la opinión del propietario respecto de la declaración. Ella puede ser positiva o negativa, pero el Ministerio no tramita ningún Decreto de declaración sin este antecedente previo.

Por último con el acuerdo positivo del Consejo pleno, la institución pide al Ministro, a través de un oficio, planos y antecedentes a fin de que dicte el Decreto correspondiente. Así se puede decir que en materia de declaraciones, el Consejo propone y el Ministerio resuelve.

\section{EFECTOS DE LA DECLARACIÓN DE MONUMENTO HISTÓRICO}

Los efectos de dar por declarado mediante decreto supremo un inmueble o sitio o área como monumento histórico los determina el artículo 11 de la ley 17.288 sobre Monumentos Nacionales el que establece: "Artículo $11^{\circ}$.- Los Monumentos Históricos quedan bajo el control y la supervigilancia del Consejo de Monumentos Nacionales y todo trabajo de conservación, reparación o restauración de ellos, estará sujeto a su autorización previa. Los objetos que formen parte o pertenezcan a un Monumento Histórico no podrán ser removidos sin autorización del Consejo, el cual indicará la forma en que se debe proceder en cada caso.”

\section{B. LIMITACIONES AL DERECHO DE DOMINIO DEL PROPIETARIO PARTICULAR}

1. A su vez si el propietario del bien inmueble declarado monumento histórico es un particular se le impone determinadas limitaciones al ejercicio de su derecho de propiedad, limitaciones que como ya hemos visto se fundan en el concepto constitucional de la función social de la propiedad y en definitiva buscan conciliar el interés particular con el bien común. Así el artículo 12 señala: "Artículo 12.- Si el Monumento Histórico fuere un inmueble de propiedad particular, el propietario deberá conservarlo debidamente; no podrá destruirlo, transformarlo o repararlo, ni hacer en sus alrededores construcción alguna, sin haber obtenido previamente autorización del Consejo de Monumentos Nacionales, el que determinará las normas a que deberán sujetarse las obras autorizadas. Si fuere un lugar o sitio eriazo, éste no podrá excavarse o edificarse, sin haber obtenido previamente autorización del Consejo de Monumentos Nacionales, como en los casos anteriores."

Ahora bien, para el evento en que se contravenga lo señalado anteriormente se establece una sanción del siguiente tenor: "La infracción a lo dispuesto en este artículo será sancionada con una multa de cinco a doscientas unidades tributarias mensuales, sin perjuicio de lo dispuesto en los artículo $25^{\circ}, 27^{\circ} \mathrm{N}^{\circ} 1$ y $38^{\circ}$ de esta ley y de la paralización de las obras mediante el uso de la fuerza pública.

2. Otra limitación al derecho de propiedad del particular cuyo bien inmueble ha sido declarado monumento histórico es aquella establecida en el artículo $15^{\circ}$ de la ley en estudio, el que dispone un derecho preferente del Estado para comprar un bien declarado monumento histórico. Al respecto el artículo determina:

"Artículo $15^{\circ}$.- En caso de venta o remate de un Monumento Histórico de propiedad particular, el Estado tendrá preferencia para su adquisición, previa tasación de dos peritos 
nombrados paritariamente por el Consejo de Monumentos Nacionales y por el propietario del objeto. En caso de desacuerdo, se nombrará un tercero por el Juez de Letras de Mayor Cuantía del departamento del domicilio del vendedor."

"Las Casas de Martillo deberán comunicar al Consejo de Monumentos Nacionales, con una anticipación mínima de 30 días, la subasta pública o privada de objetos o bienes que notoriamente puedan constituir monumentos históricos, acompañando los correspondientes catálogos. El Consejo tendrá derecho preferente para adquirirlos.”

"Corresponderá a la Dirección de Casas de Martillo aplicar las sanciones a que haya lugar."

\section{ANALISIS CRÍTICO DE LA LEY 17.288}

1. La crítica más permanente y consistente en contra de la legislación de monumentos nacionales en Chile constituída fundamentalmente por la ley 17.288, es la ausencia de beneficios tributarios o financieros para quienes son propietarios de tales bienes, sean estos muebles o inmuebles. Es así que queda la responsabilidad de mantener los monumentos en manos de sus propietarios. Tal medida es legal pero muchos la consideran injusta, y en la práctica podemos afirmar que ha significado la ruina de muchos edificios, cuyos dueños, sea por falta de recursos o por el acelerado aumento del valor del suelo, han optado por dejar que dichos bienes se destruyan paulatinamente.

2. Ahora bien, dicha ausencia de beneficios cambió con la promulgación en el año 2005 con la ley 20.033 que declaró exento del pago del 100\% del impuesto territorial a "los bienes raíces declarados monumentos históricos o públicos, acreditados por el Consejo de Monumentos Nacionales, cuando no estén destinados a actividades comerciales". Sin embargo, la crítica continúa teniendo gran fuerza puesto que la realidad es que sin recursos económicos para su conservación y desarrollo, provengan ellos del Estado, de los particulares o de las empresas, el patrimonio cultural está amenazado.

3. Otra omisión que se ha advertido en esta normativa "consiste en que la prohibición de realizar construcciones en los alrededores del monumento sólo está establecida para su propietario, pero no, por ejemplo, para un vecino que podría construir a pocos metros del inmueble, sin requerir la autorización del Consejo de monumentos, lo que aprecia su entorno. Eso puede enmendarse caso a caso con la dictación de ordenanzas locales municipales, que fijen requisitos a este respecto.

\section{DECLARACIÓN DE ZONA TÍPICA}

1. La ley 17.288 en su Título VI denominado "De la Conservación de los Caracteres Ambientales, da el siguiente tratamiento a las llamadas "zonas típicas".

"Artículo $29^{\circ}$.- Para el efecto de mantener el carácter ambiental y propio de ciertas poblaciones o lugares donde existieren ruinas arqueológicas, o ruinas y edificios declarados monumentos históricos, el consejo de monumentos nacionales podrá solicitar se declare de interés público la protección y conservación del aspecto típico y pintoresco de dichas poblaciones o lugares o de determinadas zonas de ellas encontrándose el procedimiento para declarar Zona típica en el artículo $30^{\circ}$ de la ley 17.288 que señala que la declaración 
de un lugar o sitio como zona típica se hará por medio de decreto, sin ahondar más profundamente en su procedimiento de declaración, por lo que en la práctica el consejo de monumentos ha uniformado su criterio y el procedimiento para declarar una zona típica, es el mismo empleado para la declaración de monumento histórico.

\section{Efectos de la declaración de Zona Típica}

La principal finalidad de declarar un lugar de la ciudad como zona típica tiene relación con conservar su carácter ambiental propio y tradicional, por lo que estos efectos importan ciertas restricciones a nuevas construcciones en la zona a fin de que respeten ese ambiente tradicional típico.

Así se puede observar en lo dispuesto por el artículo 30 que establece:

"Artículo $30^{\circ}$. La declaración que previene el artículo anterior se hará por medio de decreto y sus efectos serán los siguientes: 1.- Para hacer construcciones nuevas en una zona declarada típica o pintoresca, o para ejecutar obras de reconstrucción o de mera conservación, se requerirá la autorización previa del Consejo de Monumentos Nacionales, la que sólo se concederá cuando la obra guarde relación con el estilo arquitectónico general de dicha zona, de acuerdo a los proyectos presentados.

A su vez los Planes Reguladores comunales, Intercomunales y Metropolitano pueden contemplar normas, que aseguren el cumplimiento de la ley 17.288 a nivel municipal.

A fin de que efectivamente se cumpla con las disposiciones que regulan los efectos de la declaratoria de zona típica la legislación chilena contempla una sanción del siguiente tenor: "La infracción a lo dispuesto en este artículo será sancionada con multa de cinco a doscientas unidades tributarias mensuales, sin perjuicio de la paralización de las obras mediante el uso de la fuerza pública." Esta es una sanción benigna en cuanto al mínimo que señala de cinco a cincuenta unidades tributarias.

\section{DELITOS Y ACCIÓN PROCESAL ESTABLECIDOS EN LA LEY 17.288}

Además de las faltas que específicamente se tipifican en los artículos $12^{\circ}$ y $30^{\circ}$ de la Ley 17.288 que dicen relación principalmente con contravenir las restricciones a realizar obras nuevas en monumentos declarados históricos y zonas típicas sin autorización del Consejo de Monumentos Nacionales, la ley 17.288 tipifica como delito la siguiente conducta atentatoria contra el patrimonio cultural urbano imponiendo su respectiva sanción:

"Artículo 38․- El que causare daño en un monumento nacional, o afectare de cualquier modo su integridad, será sancionado con pena de presidio menor en sus grados medio a máximo y multa de cincuenta a doscientas unidades tributarias mensuales.”

A su vez establece en el mismo Título X una acción de carácter popular, pudiendo cualquier ciudadano denunciar las infracciones cometidas en contra de la ley sobre Monumentos Nacionales, teniendo como incentivo el obtener un porcentaje equivalente al 20 por ciento de la multa aplicada al infractor, como lo señala su artículo $42^{\circ}$. 
Como se ha podido observar existen en la legislación chilena mecanismos, potencialmente eficaces para identificar y proteger el patrimonio cultural urbano, sin embargo ello no se condice con el estado actual en que se encuentra este patrimonio.

La normativa principal en esta materia es la ley 17.288 del Consejo de monumentos nacionales, que ha cumplido la función de proteger las categorías de monumento histórico y de zonas típicas. Sin embargo, una de sus mayores falencias es la que al establecer limitaciones al dominio del propietario particular de estos inmuebles no le otorga beneficios o incentivos para su conservación, como se observa en el estudio del derecho comparado2 3 , siendo esto una de las principales causas del deterioro de los bienes arquitectónicos urbanos. En este sentido debería otorgársele al propietario un beneficio tributario, consistente en la reducción como gasto del impuesto a la renta, de los costos de restauración y mantenimiento de los bienes, tal como señalamos en el párrafo sobre análisis crítico de la Ley 18.288.

Debe reconocerse eso si, que la creación que hace la Ley del Consejo de la Cultura y las Artes de un fondo permanente que financia proyectos de conservación, recuperación y difusión de bienes patrimoniales intangibles y tangibles, muebles e inmuebles, protegidos por la ley $\mathrm{N}^{\circ} 17.288$, sirve de gran ayuda en la tarea de conservar el patrimonio cultural de la ciudad, para ello debiera complementarse con beneficios tributarios, de modo de conservar este patrimonio urbano, que tiene tanta significancia histórica y que es un fiel testigo de la evolución cultural del a ciudad.

\section{FUENTES}

BIBLIOGRÁFICAS

BASAEZ Yau, Patricio y DAROCH NÚÑEZ, Jaime, "Las zonas típicas de la comuna de Santiago: patrimonio arquitectónico y urbano de la capital de Chile". Santiago, Universidad de Chile, Facultad de Arquitectura y Urbanismo, Departamento de Historia y Teoría de la Arquitectura, 2009, p. 242.

BRIEVA, Amador y BASTIAS, Leonel, Ordenanza General de Urbanismo y Construcción $13^{\mathrm{a}}$ Edición, Santiago, Editorial Jurídica de Chile, 2007, p. 523.

CONSEJO DE MONUMENTOS NACIONALES, Gobierno de Chile, Convenciones internacionales sobre patrimonio cultural, $2^{a}$ serie, $4^{a}$ Edición. Santiago, Cuadernos del Consejo de Monumentos Nacionales, 2009, p. 120.

CONSEJO DE MONUMENTOS NACIONALES, Procedimiento para la declaración de un monumento nacional y requisitos mínimos para presentar una solicitud de declaración, Santiago, Documento de trabajo. Febrero, 2007, p. 5.

CABEZA MONTEIRA, Angel y SIMONETTI DE GROOTE, Susana, Legislación comparada de patrimonio cultural, Perú. España, Mejico. Santiago, Cuadernos del Consejo de Monumentos Nacionales, Segunda Serie No 13, 1996, p. 25.

\footnotetext{
${ }^{2}$ Ley Federal sobre Monumentos y zonas arquelógicas, artísticas e históricas de Mexico.

3 Ley 8853 y DL 19033 en Perú.
} 
CUADERNOS DEL CONSEJO DE MONUMENTOS NACIONALES, primera edición, Número 37.

Cuadernos del Consejo de Monumentos Nacionales, Segunda edición, número 107.

FERNANDEZ RICHARD, José, Derecho urbanístico Chile, $2^{\text {a }}$ Edición Santiago, Editorial Jurídica de Chile, 2009, p. 382. 